\title{
The Research on Adaptive Fuzzy Control Systems of Brushless DC Motors Based on DSP
}

\author{
Hong Song ${ }^{1}$, Xiaohui Zeng ${ }^{2}$ and Ming Liu ${ }^{3}$ \\ School of Automation and Electronic Information Engineering, Sichuan \\ University of Science \& Engineering, Zigong, 643000, China \\ ${ }^{1}$ sh8887878@sina.com, ${ }^{2} x h-z @$ sohu.com, ${ }^{3}$ joey_liu1988@163.com
}

\begin{abstract}
A brushless DC motor is a nonlinear system with strong couplings and multiple variables, which is difficult to establish its accurate mathematical model. In the paper, based on the analysis of brushless DC motor control systems, a adaptive fuzzy PID intelligent controller is established, in which fuzzy control theories are combined with PID control methods, making full use of super computing and reasoning abilities of digital signal processors. PID parameters can be automatically adjusted according to the actual response of fuzzy reasoning. The experimental results show that the system has a better robustness and faster response speed compared with systems with traditional PID controls .
\end{abstract}

Keywords: digital signal processor(DSP), Brushless DC motor, Adaptive, Fuzzy

\section{Introduction}

Energy saving and emission reduction have been serious global subjects for the $21 \mathrm{st}$ century. If the operation efficiency of motor systems in our country can achieve a $2 \%$ increase, 20 billion KWH electricity can saved each year. The brushless DC motor has characteristics of easy control and good speed regulating performance as the traditional dc motor, and it also has advantages of reliable operation, easy maintenance, large output torque, etc. Therefore, it has been widely used in many high-tech industries, such as robot, laser processing, submarines, and various military weapons servo system and so on. But the brushless DC motor is a nonlinear system with strong couplings and multiple variables, which is difficult to establish its accurate mathematical model. The traditional classical PID controller is difficult to satisfy the development of the motor control[1-3]. An adaptive fuzzy PID intelligent controller is established in the paper, in which fuzzy control theories are combined with PID control methods, making full use of super computing and reasoning abilities of digital signal processors. PID parameters can be automatically adjusted according to the actual response of fuzzy reasoning.

\section{The Schematic Structure of The Brushless DC Motor}

The brushless DC motor is a kind of motor with high efficiency speed control. It adopts power electronic commutator to replace mechanical commutation, using hall sensors for position sensor to replace mechanical commutator and brush in the DC motor with brush. In this way, external characteristics of DC motors with brush are retained, and many problems brought by brush are solved, such as friction sparks and noises by mechanical commutator, short service life and other deadly weakness[3-5]. The basic schematic structure of the brushless DC motor is as shown in figure 1. The conduction sequence of three-phase windings is controled by electronic commutations. Position signals of the rotor are obtained accurately to achieve correct commutations, so as to control rotations of 
the motor, and the rotation speed will not affected by the limitation of mechanical commutations which can realize high speed running. In essence, the brushless dc motor is driven by an electronic inverter, signals from a position sensor are fed back to control the AC stepping synchronous motor.

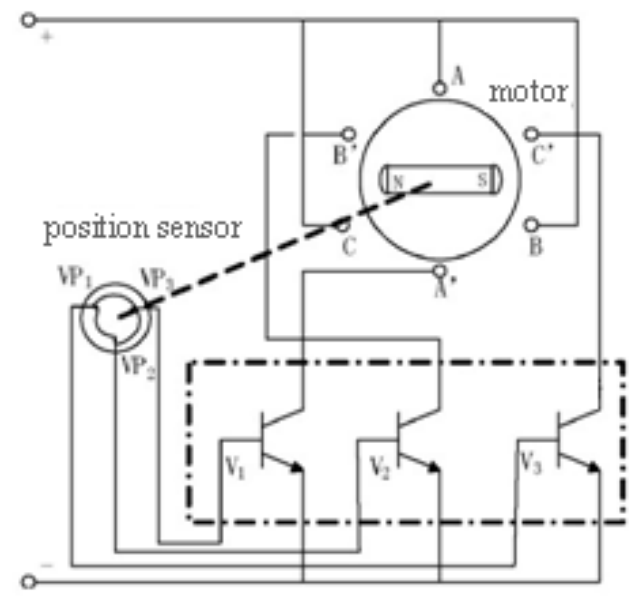

\section{Figure 1. The Basic Schematic Structure of The Brushless DC Motor}

Because the brushless DC motor is a nonlinear system with strong couplings and multiple variables, some simplifications should be made in establishing its mathematical model, such as, ignore winding inductance and mutual inductance, ignore transient processes of current changes, ignore induced current effects of the rotor, ignore the effects of air gap magnetic fields by armature reactions, etc. We set up the mathematical model of a three-phase two-pole brushless DC motor with its windings Y-connected. According to the characteristics of the brushless DC motor, we can establish its stator voltage equation, counter electromotive force equation, electromagnetic torque equation and state equation[6-7].

Three phase currents are involved in the generation of electromagnetic torque:

$$
T_{\mathrm{em}}=\frac{i_{a} e_{a}+i_{b} e_{b}+i_{c} e_{c}}{\omega}
$$

In which, $\omega$ is mechanical angular velocity of the rotor, $i_{\mathrm{a}}, i_{\mathrm{b}}, i_{\mathrm{c}}$ are the three-phase winding currents respectively (A ), $e_{\mathrm{a}}, e_{\mathrm{b}}, e_{\mathrm{c}}$ are counter electromotive forces of the threephase winding respectively.

The motion equation can be described as

$$
T_{\mathrm{em}}=T_{L}+\frac{2 J}{P} \frac{d w}{d t}+B w
$$

In which, $T_{L}$ is the load torque, $\mathrm{J}$ is the rotational inertia, $\mathrm{P}$ is the number of pole-pairs, $\mathrm{B}$ is the damping coefficient.

The position of the motor $\theta$ can be indicated as

$$
\frac{d \theta}{d t}=w
$$




\section{The Design of Adaptive Fuzzy PID Controller for The Brushless DC Motor}

Fuzzy control is the application of fuzzy set theories in control based on fuzzy inference , which has linear characteristics. It translates people's operating experiences and common sense reasoning rules into algorithm languages accepted by computers through fuzzy languages. A fuzzy controller is composed of four parts: fuzzification, knowledge base, fuzzy inference and defuzzification. Fuzzification is actually the input interface of the fuzzy control, which mainly acts to transform certain inputs into fuzzy vectors. Knowledge base generally consists of database and rule base. Fuzzy reasoning is based on fuzzy logic relations and reasoning rules. Defuzzification is to interpret control (fuzzy) quantities expressed by fuzzy reasoning practical control quantities $[6,8]$.

The traditional Proportion Integration Differentiation (PID) control is difficult to meet the performance requirements of control systems where intelligent controls must be adopted, because of the time-varying, nonlinear and strong coupling features of brushless DC motor. At present, intelligent control methods include the compound control of the fuzzy control and the artificial neural network, the fuzzy-PID control in which classic PID controls together with fuzzy algorithms, the adaptive control of the artificial neural network combined with the digital filter, etc. In this paper, an adaptive fuzzy PID intelligent controller is established by classic PID controls combined with fuzzy algorithms. A knowledge base is established and the control object is adjusted according to the fuzzy reasoning based on the actual responses. Therefore, PID parameters can be automatically adjusted[8-9].

Inputs of the adaptive fuzzy PID controller are the error E and the change rate EC. The adaptive fuzzy PID controller is achieved through PID control parameters on-line adjustments using fuzzy theories. It has not only flexible and adaptable advantages of fuzzy control algorithms, but also no steady-state error characteristic of the PID control. The function relation between the change rate EC, the error E and PID parameters KP, KI, $\mathrm{KD}$ established by fuzzy theories is

$K=F(|E|,|E C|)$

PID parameters are adjusted on-line according to the fuzzy reasoning to satisfy different errors and change rates, and then good dynamic and static performances of the controlled objects can be achieved. the fuzzy PID controller has two inputs E and EC, three PID parameters outputs KP, KI, KD. Assume the fuzzy subset of input variables $|\mathrm{E}|$ and $|\mathrm{EC}|$ are negative big, negative middle, negative small, zero, positive small, positive middle, positive big $\}$, noted as $\{\mathrm{NB}, \mathrm{NM}, \mathrm{NS}, \mathrm{ZO}, \mathrm{PS}, \mathrm{PM}, \mathrm{PB}\}$. The error $\mathrm{E}$ and the error change EC are quantified into region $(-3,3)$. The fuzzy subset of output parameters KP, KI, KD are $\{\mathrm{ZO}, \mathrm{PS}, \mathrm{PM}, \mathrm{PB}\}$, and they are quantified into region $(0,3)$. The membership function curves of the input and output are as shown in figure 2 respectively.

Simulations of the control system are carried on through Matlab/Simulink. Parameters of the brushless DC motor are as follows: the self inductance of the stator windings $\mathrm{L}=0.02 \mathrm{H}$, the resistance of the stator windings $\mathrm{R}=1 \Omega$, mutual inductance $\mathrm{M}=0.061 \mathrm{H}$, damping coefficient $\mathrm{B}=0.0002 \mathrm{~N} \cdot \mathrm{m} \cdot \mathrm{S} / \mathrm{rad}$, rotational inertia $\mathrm{J}=0.005 \mathrm{~kg} \cdot \mathrm{m}^{2}$, the number of pole pairs $\mathrm{P}=1$, rated speed $\mathrm{n}=100 \mathrm{r} / \mathrm{min}$. A double closed-loop control of the velocity and current is adopted in the control system. 

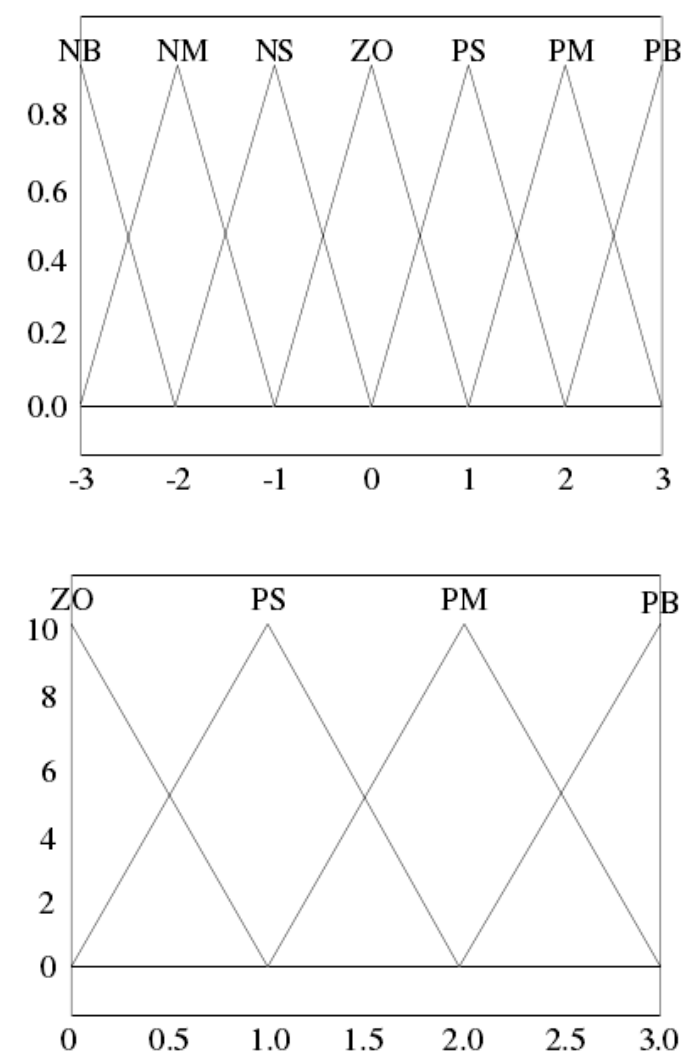

Figure 2. Membership Function Curves

The response curve of the control system for the brushless DC motor with the fuzzy PID control is as shown in figure 3. As shown from simulation results, the dynamic response of the system is improved obviously, and at the same time, the steady-state errors are small and the adaptability and robustness of parameters are great.

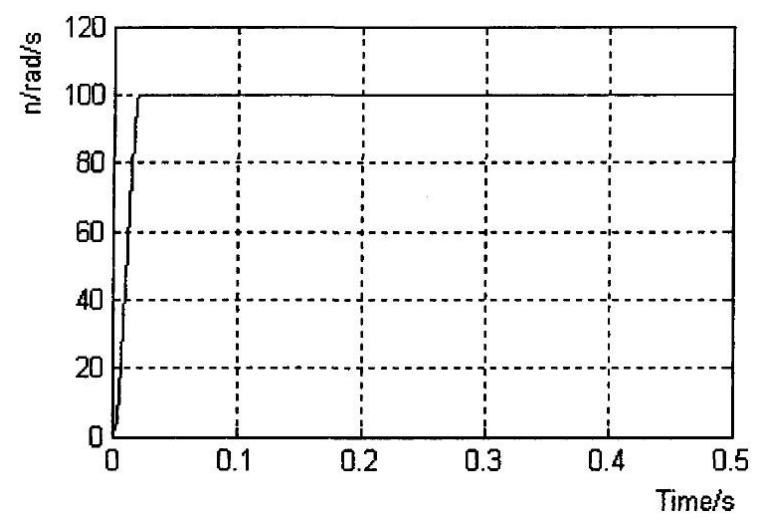

Figure 3. The Speed Response Curve of The System Based on Fuzzy PID Control 


\section{The Control System Design for The Brushless DC Motor Based on DSP}

Control modes of the brushless DC motor include three ways - open loop control, single closed-loop control, double closed-loop control. Double closed-loop control mode is adopted because the system can adjusted automatically and responded to instructions greatly under situations when loads change or the system is disturbed by external factors[10-12].

The hardware structure of the brushless DC motor control system adopts a modular design method. Relative circuits are designed according to different function modules, as shown in figure 4 . The three main parts of the system are the DSP controller, drive circuits, three-phase inverter. The brushless DC motor is controlled by PWM. Drive circuits are composed of drive module IR2132S supplied by the international rectifier company. A stable working voltage is supplied to the motor after the processing of threephase voltage regulator, three-phase rectifier and three-phase inverter. Position sensors send position signals of the brushless DC motor to the QEP terminal of the DSP through photoelectric encoders for steering and speed judgments. The DSP controller realizes a effective and precise control of the brushless DC motor through speed and current double closed-loop control system which adjusts the speed and the current according to a given speed signal, a feed-back speed signal and a feed-back current signal.

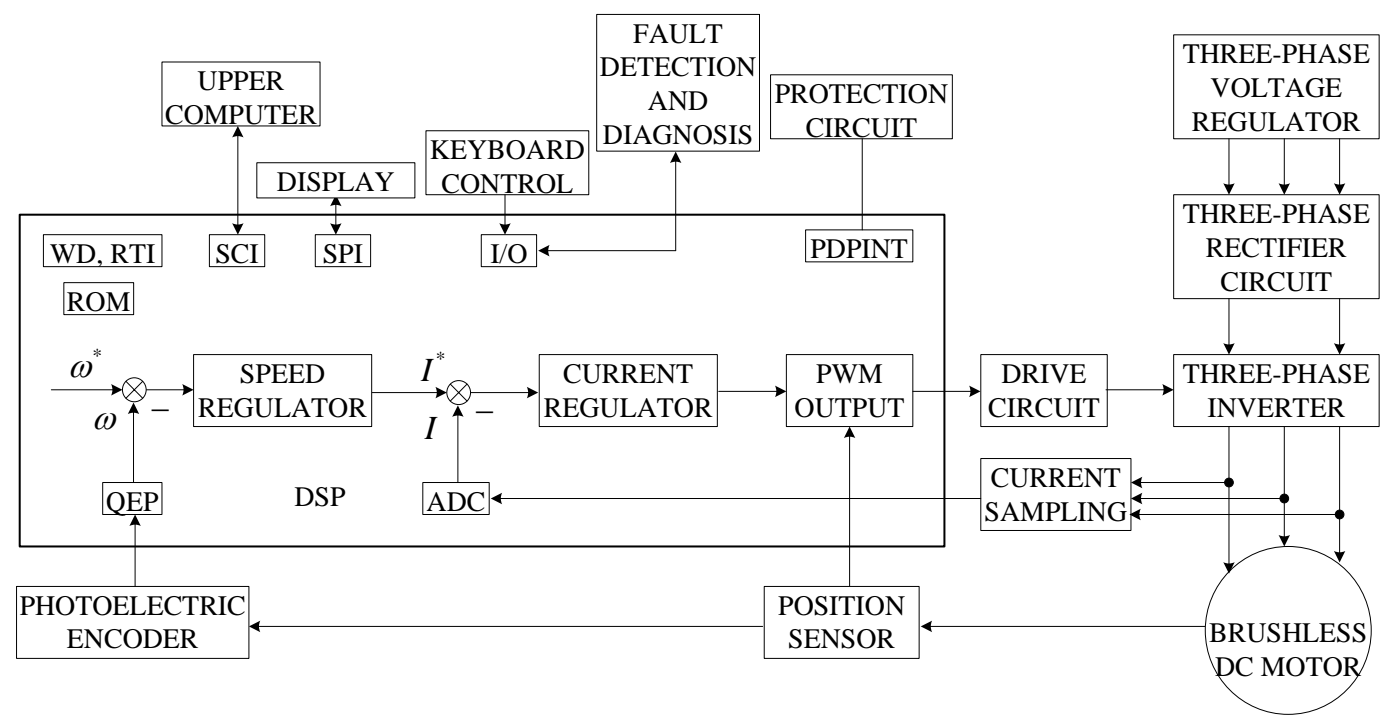

Figure 4. The Block Diagram of the Control System Hardware

The central controller is the key for the control of the brushless DC motor, which has a direct influence on the performance of the control system. A good central controller has a stable performance and is easy to transplant and control, here we choose TMS320LF2407A type controller from the TI company. It's a fixed-point DSP controller with high performance static CMOS technologies. The execution speed of the controller is 40MIPS, which improve the real-time control ability of the controller greatly. There is a on-chip 32K 16-bit flash programmable memory which can be encrypted. The controller also has a 544 words dual-access random access memory DARAM, a $2 \mathrm{~K}$ words singleaccess RAM, and a total of $192 \mathrm{~K}$ words extensible external memory. The controller is widely used in the industrial control fields, because it is a programmable ideal processor with high performance, low power consumption and small size. 


\section{Software Design}

In order to make the control system is easy to be modified debugged and maintained, a modular design structure is adopted in the software design of the system, which has strong versatility and portability. The control software of the system has mainly two parts: the main program and interrupt subroutine. The main program includes three parts: system initialization, capturing current position of the motor and setting interrupt logic. The interrupt subroutine has position signal capturing interrupt subroutine, current sampling interrupt subroutine, fault protection interrupt subroutine, etc. The whole block diagram of the system is as shown in figure 5 .

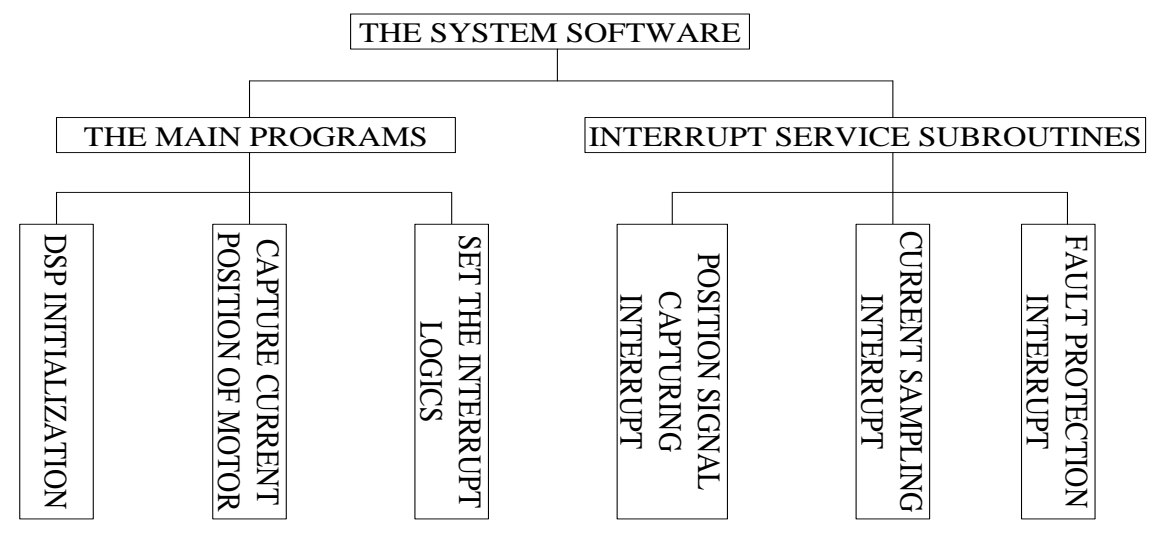

Figure 5. The Block Diagram of the System Software

\section{Conclusions}

The brushless DC motor has advantages of simple control, reliable operation, easy maintenance, large output torque, good speed regulation performance. But it is nonlinear system with strong couplings and multiple variables. Hence the traditional classical PID controller can't meet the current development requirements of the motor. An adaptive fuzzy PID intelligent controller is established in the paper, in which fuzzy control theories are combined with PID control methods, making full use of super computing and reasoning abilities of digital signal processors. PID parameters can be automatically adjusted according to the actual response of fuzzy reasoning. The results show that the system has a better robustness and a faster speed response compared to the traditional PID controller.

\section{Acknowledgments}

The research work was financially supported by the artificial intelligence key laboratory of Sichuan province (2014RYY005, 2015RYY001), and develop project of Sichuan University of Science \& Engineering (2012PY18).

\section{References}

[1] J. Tan, "Technologies of Permanent Magnet Brushless DC motor", Mechanical Industry Press, Beijing (2011).

[2] B. K.Bose, "Modem Power Electronics and AC Drives", Mechanical Industry Press, Beijing(2003).

[3] Gang Liu, "Control Technologies and Applications of Permanent Magnet Brushless DC Motor", Mechanical Industry Press, Beijing (2009).

[4] C. Xia, "The Control System of Brushless DC Motor", Science Press, Beijing (2009).

[5] X. Pang, "The Research and Design of the Experiment System for Brushless DC Motor Based on DSP", Shandong University master degree thesis (2008).

[6] M. Liu \& H. Song, "The Application of Adaptive Fuzzy PID Intelligent Controller in the Speed Control System of the Brushless DC Motor", Motor and Control Application, vol. 39, no. 11,(2012), pp.22-25. 
[7] W. Wang, J. Feng \& J. Xu, "New Strategy of Torque Ripple Minimization of Permanent Magnet Brushless DC Motor", Electronic Design Engineering, vol. 18, no. 4, (2010), pp.108-111.

[8] J. Liu, "Advanced PID Control and its MATLAB Simulations", Electronic Industry Press(2004).

[9] Z. Lei, Q. Wenlong, “ Commutation Torque Ripple Restraint in BLDC Motor over Whole Speed Range", Electrical Machines and Systems, ICEMS Proceedings of the Eighth International conference (2004), pp.1501-1506.

[10] Y. Chao, X. Zhang, K. Li \& F. Yu, "Drive System of the Brushless DC Motor for Load Commutation Based on DSP", Power Electronic Technology, vol. 39, no. 2, (2005), pp.36-38.

[11] H. He, W. Liu \& B. Lang, "Torque Characteristics Research of Non-commutation Interval of the Permanent Brushless DC Motor”, Electric Drive, vol. 37, no. 10, (2007), pp.34-38.

[12] P. Ling, K. Wei \& Z. Zhang, "A Novel Control Scheme to Suppress the Commutation Torque ripple in BLDCM", Journal of Electrical Engineering, China, vol. 26, no. 3, (2006), pp.153-158.

\section{Authors}

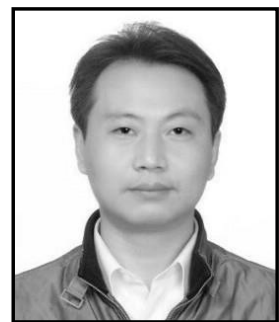

Hong Song, He is a Professor in sichuan University of Science \& Engineering, China. His research interests are automatic control technologies and power electronic technologies. 
International Journal of Control and Automation Vol. 9, No. 3 (2016) 